\title{
Study on Automatic Solar Heat Insulated and Cooling Device of Car
}

\author{
Gui-Yue CHEN ${ }^{1, a}$, Qi-Juan CHEN ${ }^{2}$, Chang LIU ${ }^{3}$ and Qi WANG ${ }^{4}$ \\ ${ }^{1,2,3,4}$ School of Power and Mechanical Engineering, Wuhan University, Wuhan Hubei, China, 430072
}

\begin{abstract}
In view of the common device for heat insulated and cooling of car, an improved new scheme which drove by solar energy is put forward. In this study, the transmission device are arranged inside the automobile, the thin-film solar is composited into the heat insulated and cooling material. Thus, the whole device can be driven by the energy from the photovoltaic conversion, which is clear and zero-pollution. The theoretical energy consumptions and preventable gas emissions are calculated to verify the environmental savings of the device. The results show that it has promising application prospect since it is not only environmentally friendly but also save and convenient as compared to the conventional device.
\end{abstract}

\section{Introduction}

In the case of serious shortage of parking spaces in China, the average annual growth rate of motor vehicles is still more than $15 \%$ [1-2].So that most of the private cars can often only be parked in the light of the sun. The test shows that temperature in car can be as high as $64.9 \square$ after $15 \mathrm{~min}$ at $32.5 \square$ outdoor temperature.

Strong solar radiation will be harmful for the car's leather seats and dashboard as well as other facilities, produce formaldehyde, benzene and other harmful substances, accelerate the aging of components in the car, extremely easy to cause it to spontaneous combustion. There are great health and safety worries. In addition, with the increase of vehicle temperature and the time that the owner open the air conditioning to cooling before driving, the fuel consumption, carbon dioxide, PM2.5 and other harmful exhaust emissions has been increased. According to statistics, when the car is idling, the fuel consumption with the air conditioning opening is $15 \%$ higher than the normal. More than this, with the incomplete combustion of gasoline, the release of the $\mathrm{CO}$, NO and other harmful gases reaches to 5 times as the normal state [3-4].Not only a waste of non-renewable energy, but also pollution of the atmospheric environment. Urban traffic pollution of China accounts for $70 \%$ to $90 \%$ of air pollution [5], and carbon dioxide emission ranks first in the world. Therefore, reducing carbon dioxide emission and gasoline consumption is a task which brooks no delay.

At present, the automotive insulated cooling devices on the market are mostly sucker sun block (plate), they have some disadvantages, such as manual arrangement, carrying inconvenient and not easy to fix. They do have some cooling effect, but it is poor, so that the frequency of use is not high. In addition, it is in 1978 that China used solar energy in the car for the first time, mainly about air conditioning and refrigeration technology [6-8].Thus, to provide simple and convenient vehicle

\footnotetext{
${ }^{a}$ Corresponding author: yue1020@whu.edu.cn
} 
insulation cooling device is in line with people's expectations and Chinese energy sustainable development goals.

On this basis, a new type of heat insulated and cooling device is presented in this paper. The transmissions and units are arranged in the vehicle body. After parking, the heat insulated device is automatically raised or lowered by the control circuit and the motor, and is fixed in the proper position. And the solar film and thermal insulation material are composited, to drive the entire device by the energy comes from photoelectric conversion. It can avoid the manual arrangement / removal of the sun shading device, which is convenient, and could achieve the energy saving and environmental protection.

\section{Design}

In order to reduce the occupancy of the interior space as much as possible, the device is arranged in the vehicle body of the front and rear window, to control its movements by the remote control. The control box is small, and placed on the instrument table. An intermediate sectional view of the mounting position of the integrated device is shown in Figure 1.

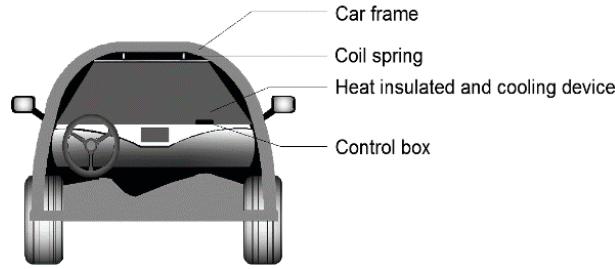

Figure 1. The intermediate sectional view of the mounting position of the device

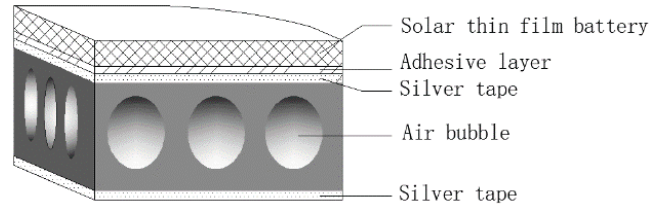

Figure 2. The schematic diagram of heat insulated and cooling and photoelectric conversion composite material

The material used in this project is composited by heat insulated and cooling material and photoelectric conversion material, the structure diagram shown in Figure 2.Dye-sensitized solar cell is used to achieve photoelectric conversion, which has the advantages of simple production process, stable performance, low cost and no pollution to the environment. Its development is very fast, researchers are constantly updating in materials, preparation techniques and basic research [9]. The current laboratory efficiency has exceeded $12 \%$, and in standard light conditions, the highest photoelectric conversion rate can reach $11.18 \%$ [10-12].Insulation layer is a silver tape bubble diaphragm, in order to obtain a better heat insulation effect, the insulation layer adopts two layers of silver tape and the multiple bubbles separated form in the middle.

\section{Theoretical calculation}

\subsection{Device selection}

Taking into account the size of the space inside the vehicle and the energy consumption of the installation, the parameters of the motor and the battery are shown in Table 1. 
Table 1. The parameters of the motor and the battery

\begin{tabular}{|c|c|c|c|}
\hline \multicolumn{2}{|c|}{ Motor } & \multicolumn{2}{c|}{ Battery } \\
\hline Type & DC & Voltage & $12[\mathrm{~V}]$ \\
\hline Rated power & $120[\mathrm{~W}]$ & \multirow{2}{*}{ Model } & \multirow{2}{*}{$6[\mathrm{~V}] 4.5[\mathrm{AH}]$} \\
\hline Shaft diameter & $8[\mathrm{~mm}]$ & & \multirow{2}{*}{$70 \times 45 \times 100\left[\mathrm{~mm}^{3}\right]$} \\
\cline { 1 - 2 } Outside diameter & $9[\mathrm{~mm}]$ & Size & \\
\cline { 1 - 2 } Axis length & $30-50[\mathrm{~mm}]$ & & \multirow{2}{*}{$0.65[\mathrm{~kg}]$} \\
\hline Voltage & DC $12[\mathrm{~V}]$ & Net weight & \\
\cline { 1 - 2 } & $12[\mathrm{r} / \mathrm{min}]$ & & \\
\cline { 1 - 2 }
\end{tabular}

\subsection{Calculation of the energy consumption of the device and light time}

Air quality can be derived from (1) type:

$$
m=\frac{1}{\cos (90-\theta)+0.50572(6.07995+\theta)^{-1.6364}}
$$

Solar radiation flux is:

$$
I_{m}=I_{0} y^{m}
$$

In the formula, $\mathrm{m}$ is atmospheric quality; $\theta$ is the included angle between the incident light and the horizontal plane $\left(\theta=45^{\circ}\right) ; \mathrm{I}_{0}$ is solar constant, and $\mathrm{I}_{0}=1353 \mathrm{~W} / \mathrm{m}^{2} ; \mathrm{I}_{\mathrm{m}}$ is radiation flux of solar radiation through $\mathrm{M}$ atmospheric mass; $\mathrm{y}$ is atmospheric transparency. Under normal circumstances, the best sunny day desirable $\mathrm{y}=0.85$, the good sunny day desirable $\mathrm{y}=0.80$, the moderate sunny day desirable $y=0.65$, the poor sunny day desirable $y=0.53[13-15]$.This is calculated on a poor sunny day, take $\mathrm{y}=0.53$. Substituting data can be obtained: $\mathrm{m}=1.4126, \mathrm{I}_{\mathrm{m}}=551.836 \mathrm{~W} / \mathrm{m}^{2}$.

The motor consumes energy is:

$$
Q_{1}=2 \times P_{1} \times t
$$

The daily operating time of the motor is:

$$
t=t_{1} \times N
$$

The energy formula of dye-sensitized solar cell is:

$$
Q_{2}=2 \times \tau \times I_{m} \times \eta \times A \times t_{2}
$$

The energy formula of control box is:

$$
Q_{3}=P_{3} \times t
$$

By the law of conservation of energy we can see that the electricity energy of solar cells produced and consumed by the motor is equal, namely:

$$
Q_{1}+Q_{3}=(1-\xi) Q_{2}
$$

In the formula, $Q_{1}$ is the energy consumed by the motor; $Q_{2}$ is the solar energy received by the dye-sensitized solar cell; $\mathrm{t}$ is the daily operating time of the motor; $\mathrm{P}_{1}$ is the power of the motor; $t_{1}$ is the time of the motor lift and down once; Nis the number of movements within a day (take 4 times); $A$ is the area of the dye-sensitized solar cells; $\eta$ is the conversion efficiency of dye-sensitized solar cell, taking into account the conversion efficiency is difficult to achieve the highest in the practical 
application, here take $8 \% ; \tau$ is the automotive glass transmission rate; $\xi$ is the loss of energy in the circuit (take $\xi=0.2$ ); $\mathrm{Q}_{3}$ is the energy consumed by the control box; $\mathrm{P}_{3}$ is the power of the control box (work for $30 \mathrm{~W}$, standby power is negligible); $\mathrm{t}_{2}$ is the time of exposure of the dye-sensitized solar cell.

Taking $\mathrm{t}_{1}=20 \mathrm{~s}$, in accordance with the provisions of the State Ministry of Public Security traffic safety regulations, the transmittance of the front windshield must be greater than $70 \%$. Therefore, taking $\tau=0.7$ here. Dye-sensitized solar cell parameters: Radiation flux: $\mathrm{I}_{\mathrm{m}}=551.836 \mathrm{~W} / \mathrm{m}^{2}$, Area: $\mathrm{A}=100 \times 50=5000 \mathrm{~cm}^{2}=0.5 \mathrm{~m}^{2}$, it can be considered that the time of exposure of the dye-sensitized solar cell $\mathrm{t}_{2}=777.842 \mathrm{~s} \approx 13 \mathrm{~min}$.

From the above calculation can be seen, in the case of poor sunny days and moderate latitudes of $45^{\circ}$, it is need $13 \mathrm{mins}$ for sun exposure to meet the energy consumption of the device every day. If there is more sunny weather and lower latitudes, the time required will be less.

\subsection{Device lift control}

(1) The use of electronic controller to achieve the motor start and stop, forward and reverse

The circuit is controlled by the remote control device. When the controller emits a signal "L", the motor rotates forward and the heat insulated cooling device rises. After reaching the specified position, touching the limit switch $\mathrm{SQ}_{1}$, cutting off the power supply, stopping the tubular motor, and limit the mechanical limit device on the tubular motor. On the contrary, when the controller emits a signal "down", the motor reverses and the heat insulated cooling device down. After reaching the specified position, touching the limit switch $\mathrm{SQ}_{2}$, cutting off the power supply, stopping the tubular motor, and limit the mechanical limit device on the tubular motor. Control circuit ladder as shown in Figure 3.

(2) The use of remote control to achieve remote control

When touching the electric switch "on", at the same time trigger the electronic lock control circuit "open" and the electronic controller circuit "down", through the transmitter to send signals to achieve lock car at the same time the heat insulated cooling device automatically rising. Similarly, when touching the electric switch "lock", at the same time trigger the electronic lock control circuit "lock" and the electronic controller circuit "L", through the transmitter to send signals to achieve lock car while the heat insulated cooling device automatically rises. The schematic diagram shown in Figure 4.

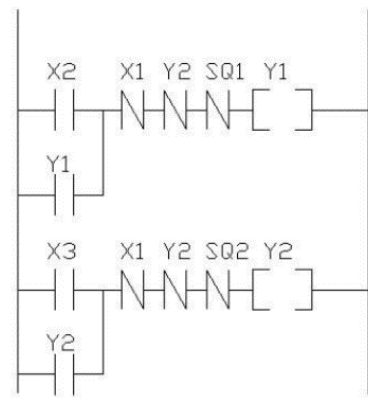

Fig. 3. Control circuit ladder

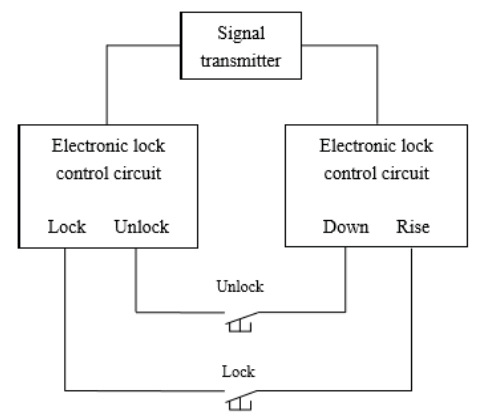

Fig. 4. The schematic diagram of remote control principle 


\section{Test and analysis}

\subsection{Test program and effect}

In order to estimate the time when the vehicle temperature dropped to $28^{\circ} \mathrm{C}$ in the absence of a sun shading device, the following tests were conducted in comparison with the case of a car with a shading device. Using two cars of the same color, displacement (both are 1.6L) and models as the object of this experiment. One installed the heat insulated and cooling device, and the other with a "naked sun". Before the test, the temperature inside the two cars was controlled at $28^{\circ} \mathrm{C}$, and then exposed the two vehicles at the same time. The test of the warming-up phase began at $2 \mathrm{pm}$ and ended at $3: 15 \mathrm{pm}$, took place every 15 minutes to measure the outside air temperature and the inside air temperature. The measurement results are shown in Table 2.

Table 2. The change of the temperature inside the car

\begin{tabular}{|c|c|c|c|}
\hline \multirow{2}{*}{ Time } & outside air temperature $\left[{ }^{\circ} \mathrm{C}\right]$ & \multicolumn{2}{|c|}{ inside air temperature $\left[{ }^{\circ} \mathrm{C}\right]$} \\
\cline { 3 - 4 } & 32.0 & With the device & Without the device \\
\hline $14: 00$ & 34.0 & 28.0 & 28.0 \\
\hline $14: 15$ & 33.0 & 35.1 & 38.1 \\
\hline $14: 30$ & 32.8 & 37.3 & 40.3 \\
\hline $14: 45$ & 32.0 & 38.5 & 42.2 \\
\hline $15: 00$ & 32.0 & 39.4 & 43.5 \\
\hline $15: 15$ & 40.2 & 44.0 \\
\hline
\end{tabular}

After rising the inside air temperature, cooling two cars immediately. According to the measurement, it required for 12 minutes and 03 seconds to cool the vehicle temperature down to the initial $28^{\circ} \mathrm{Cof}$ the car which was without the heat insulated cooling device by air conditioning, but it took only 7 minutes and 33 seconds for the car which was install the insulated cooling device. The use of insulated cooling device can reduce the air conditioning cooling time of 4 minutes and 30 seconds.

\subsection{Vehicle Emissions Analysis}

\subsubsection{Automobile fuel consumption calculation}

For the car with a displacement of $1.6 \mathrm{~L}$, idle fuel consumption when open air conditioning is $1.12 \mathrm{~L} / \mathrm{h}$. Then the per minute fuel consumption of the parking idling state of the open air-conditioning is:

$$
1.12 \mathrm{~L} \div 60 \mathrm{~min} \approx 0.0187 \mathrm{~L} / \mathrm{min}
$$

Check the density of gasoline is $0.725 \mathrm{~kg} / \mathrm{L}$. Then the consumption of gasoline quality of the car which is in the idle state of parking and taking more 4 minutes and 30 seconds to open the air conditioning is:

$$
0.0187 \mathrm{~L} / \mathrm{min} \times 0.725 \mathrm{~kg} / \mathrm{L} \times 4.50 \mathrm{~min} \approx 0.0610 \mathrm{~kg}
$$

\subsubsection{Calculation of Carbon Emissions}

The exhaust emissions of automobile engine cylinder accounted for about $65 \%$ of vehicle exhaust emissions [16]. According to the potential emission coefficient of $\mathrm{CO}_{2}$ and the average low calorific value of fuel, the amount of $\mathrm{CO}_{2}$ produced by fuel combustion can be calculated: 
(1) The basic data

According to the data of the National Development and Reform Commission of the People's Republic of China Energy Information Dissemination Center released, the potential emission coefficient and the average low calorific value of $\mathrm{CO}_{2}$ are shown in Table 3 [17].

Table 3. The potential emission coefficient and the average low calorific value of $\mathrm{CO}_{2}$

\begin{tabular}{|c|c|c|c|}
\hline Fuel type & $\begin{array}{c}\text { the potential emission coefficient of } \\
\mathbf{C O}_{\mathbf{2}}[\mathbf{k g} / \boldsymbol{G} \boldsymbol{J}]\end{array}$ & Energy name & $\begin{array}{c}\text { the average low calorific } \\
\text { value }[\mathbf{k J} / \mathbf{k g}]\end{array}$ \\
\hline gasoline & 69.363 & gasoline & 43124 \\
\hline Diesel & 74.024 & Diesel & 42705 \\
\hline natural gas & 56.224 & natural gas & 35588 \\
\hline
\end{tabular}

(2) The amount of $\mathrm{CO}_{2}$ is calculated as follows:

$$
m_{\mathrm{CO}_{2}}=m_{f} Q_{l} k
$$

In the formula, $\mathrm{m}_{\mathrm{CO}_{2}}$ is the mass of $\mathrm{CO}_{2}$ that produced by fuel combustion $(\mathrm{kg}) ; \mathrm{m}_{\mathrm{f}}$ is the quality of fuel consumption $(\mathrm{kg}) ; Q_{l}$ is the average low calorific value of fuel $(\mathrm{kJ} / \mathrm{kg}) ; \mathrm{k}$ is the potential emission coefficient of $\mathrm{CO}_{2}(\mathrm{~kg} / \mathrm{GJ})$. After calculation, the quality of $\mathrm{CO}_{2}\left(\mathrm{~m}_{\mathrm{CO}_{2}}\right)$ that produced by $1 \mathrm{~kg}$ of gasoline combustion is $2.99 \mathrm{~kg}$. Then the mass of $\mathrm{CO}_{2}$ that produces in the idle state of parking and taking more 4 minutes and 30 seconds to open the air conditioning is:

$$
2.99 \times 0.0610=0.1824(\mathrm{~kg})
$$

In the state of normal temperature and pressure, the density of $\mathrm{CO}_{2}$ is $1.429 \mathrm{~g} / \mathrm{L}$, then the volume of $\mathrm{CO}_{2}$ that produces in the idle state of parking and taking more 4 minutes and 30 seconds to open the air conditioning is:

$$
0.1824 \times 10^{3} \div 1.429=127.642(L) \approx 0.128\left(\mathrm{~m}^{3}\right)
$$

\subsubsection{The amount of harmful gas produced by the automobile under different conditions}

The amount of harmful gas produced by vehicles under different conditions is shown in Table 4.

Table 4. The amount of harmful gas produced by vehicles under different conditions

\begin{tabular}{|c|c|c|c|}
\hline \multirow{2}{*}{ Vehicle type } & \multirow{2}{*}{ Operating condition } & \multicolumn{2}{|c|}{ Harmful gas emissions } \\
\cline { 2 - 3 } & & $C O[\%]$ & $H C[\mathrm{mg} / \mathrm{L}]$ \\
\hline \multirow{3}{*}{ Gasoline vehicles } & Idle & $4.0 \sim 10$ & $300 \sim 2000$ \\
\cline { 2 - 4 } & Speedup $0 \sim 40[\mathrm{~km} / \mathrm{h}]$ & $0.7 \sim 5.0$ & $300 \sim 600$ \\
\cline { 2 - 4 } & Uniform speed $40[\mathrm{~km} / \mathrm{h}]$ & $0.5 \sim 4.0$ & $200 \sim 400$ \\
\hline
\end{tabular}

For a car with the displacement of $1.6 \mathrm{~L}$ (to four-cylinder machine, for example), taking the median $\mathrm{CO}$ emissions, a known: $\phi_{\text {idle }}=7 \%, \phi_{\text {speedup }}=2.85 \%, \phi_{\text {uniform speed }}=2.25 \%$ (Since the proportion of $\mathrm{HC}$ is too small, it is ignored here). According to the calculation formula of $\mathrm{CO}$ emissions:

$$
V_{n}=V \times f \times t \times \varphi_{n}
$$

Then in the idle state, the engine speed of the car is about $600-1000 \mathrm{r} / \mathrm{min}$, here take $800 \mathrm{r} / \mathrm{min}$, the emission amount of $\mathrm{CO}$ is: 


$$
V_{\text {idle }}=1.6 \times \frac{800}{60 \times 2} \times 270 \times 7 \% \approx 0.202\left(\mathrm{~m}^{3}\right)
$$

When speed of the car is up to $40 \mathrm{~km} / \mathrm{h}$, because of its engine speed rising, in order to make calculation convenient, here take the middle value of $1000 \mathrm{r} / \mathrm{min}$, then the emission amount of $\mathrm{CO}$ in the accelerated state is:

$$
V_{\text {speedup }}=1.6 \times \frac{1000}{60 \times 2} \times 270 \times 2.85 \% \approx 0.103\left(\mathrm{~m}^{3}\right)
$$

When the car runs with a constant speed of $40 \mathrm{~km} / \mathrm{h}$, the engine speed is about $1300 \mathrm{r} / \mathrm{min}$, the emission amount of $\mathrm{CO}$ is:

$$
V_{\text {uniform speed }}=1.6 \times \frac{1300}{60 \times 2} \times 270 \times 2.25 \% \approx 0.105\left(\mathrm{~m}^{3}\right)
$$

It can be seen that the emission of $\mathrm{CO}$ and $\mathrm{HC}$ is 1.96 times as fast as that of accelerating motion and 1.92 times of isokinetic velocity when the vehicle is running at idle. But in the crowded areas and traffic, exhaust emissions of pollutants accounted for about $40 \%$ of PM2.5. Moreover, in the idle state of operation, the resulting $\mathrm{CO}$ is 1.58 times of $\mathrm{CO}_{2}$, indicating that in this state, the gasoline is not completely burned serious. The automobile exhaust is harmful to human health, it can cause eye irritation, tearing, headache, sore throat, cough, asthma, difficulty in breathing and other symptoms [18]. Therefore, it is particularly important to reduce vehicle exhaust emissions.

\section{Conclusion}

This study promotes a heat insulated and cooling device from install manually to lift and fall automatically with the open and close state of the car electric lock, which is more convenient and flexible. Meanwhile, the device use the environmental solar power as the energy source, which will not produce additional energy consumption. Theoretically, only 13 minutes of sunlight exposure can satisfy the energy requirement for a whole day. Thus, extra power from gas and vehicle exhaust emission can be both reduced, which confirms to the national energy conservation and emission reduction policy. Additionally, the device is set inside the automobile without obstructing the divers' sight, which is favor of diving safety. Based on the benefits listed above, this device is promising. In the future production process, the automobile makers can install these for cars before delivery to improve the performance and make them more impressive.

\section{References}

1. J. X. Wang. People's Public Transportation. 01, 15-18 (2001).

2. F. C. Han, J. S. Wang. Journal of People's Public Security University of China (Science and Technology). 02, 89-92 (2006).

3. Y. P. Wang, G. C. Jiao, B. C. Zou. Forest Engineering. 06, 29-30 (1999).

4. Z. C. Xu. Anhui Agricultural Science Bulletin. 06,100-101 (2008).

5. Q. Y. Yang, S. Y. Chen, Wang Zhengbin. Sichuan Environment. 01, $84-87$ (2004).

6. H. Meng, Y. J. Chen. Forum on Science and Technology in China. 05, 96-101 (2009).

7. Z. Q. Yin, X. J. Meng. Acta Energiae Solaris Sinica. 05, 575-588 (2003).

8. Y. F. Zhao, J. Wan, Z. P. Zhu, etc. Tractor \& Farm Transporter. 05, 16-19+24 (2011).

9. O' Regan Brian C, Grätzel Michael. Nature. 353(6346), 737-738 (1991).

10. A. Yella, H. W. Lee, Grätzel Michael, et al. Science. 344(6060), 629-633 (2011).

11. F. T. Kong, S. Y. Dai. Progress in Chemistry. 11, 1409-1424 (2006).

12. X. Q. Fang, J. Zhang, Ding Yong, etc. Acta Energiae Solaris Sinica. 12, 2222-2227 (2013).

13. B. Z. Wang, G. T. Pan. Acta Energiae Solaris Sinica. 01, 13-22(1981).

14. X. J. Fang, Weng Duming. Acta Geographica Sinica. 01, 52-59 (1988). 
15. H. J. Li, C. Q. Zhu. Acta Energiae Solaris Sinica. 01, 105-112(1983).

16. D. X. Shen, H. D. Chen, Q. Tian. Chinese Journal of Environmental Engineering. 06, 24-34 (1997).

17. G. H. Wu. Theory Journal. 03, 61-65 (2012).

18. Y. B. Cheng, Y. L. Jin, Y. C. Liu. Journal of Hygiene Research. 05, 504-507 (2003). 